\title{
Use of coupled ozone fields in a 3-D circulation model of the middle atmosphere
}

\author{
T. Reddmann, R. Ruhnke and W. Kouker \\ Institut für Meteorologie und Klimaforschung, Forschungszentrum Karlsruhe, Postfach 3640, \\ 76021 Karlsruhe, Germany
}

Received: 27 October 1997 / Revised: 26 August 1998 / Accepted: 15 September 1998

\begin{abstract}
With a detailed chemistry scheme for the middle atmosphere up to $70 \mathrm{~km}$ which has been added to the 3-D Karlsruhe simulation model of the middle atmosphere (KASIMA), the effects of coupling chemistry and dynamics through ozone are studied for the middle atmosphere. An uncoupled version using an ozone climatology for determining heating rates and a coupled version using on-line ozone are compared in a 10 -month integration with meteorological analyses for the winter 1992/93 as the lower boundary condition. Both versions simulate the meteorological situation satisfactorily, but exhibit a too cold lower stratosphere. The on-line ozone differs from the climatological data between 20 and $40 \mathrm{~km}$ by exhibiting too high ozone values, whereas in the lower mesosphere the ozone values are too low. The coupled model version is stable and differs only above $40 \mathrm{~km}$ significantly from the uncoupled version. Direct heating effects are identified to cause most of the differences. The well-known negative correlation between temperature and ozone is reproduced in the model. As a result, the coupled version slightly approaches the climatological ozone field. Further feedback effects are studied by using the on-line ozone field as a basis for an artificial climatology. For non-disturbed ozone conditions realistic monthly and zonally averaged ozone data are sufficient to determine the heating rates for modelling the middle atmosphere.
\end{abstract}

Key words. Atmospheric composition and structure (middle atmosphere - composition and chemistry), Meteorology and atmospheric dynamics (middle atmosphere dynamics).

\section{Introduction}

The dynamic state of the atmosphere as a whole and the middle atmosphere in particular is strongly influenced by the chemistry of radiative active gases as their concentrations determine the amount of heating and cooling in the atmosphere, the primary source of all kinds of atmospheric circulation. A realistic model of the middle atmosphere should therefore include the main chemical processes and the chemical module should be coupled to the dynamical part by physical parametrizations of the heating and cooling rates of the radiatively active gases. This interaction between chemistry and dynamics is most important for ozone which is destroyed and produced within the middle atmosphere. Besides water vapour in the lowermost stratosphere, it is the most important gas in terms of radiative chemical coupling for the middle atmosphere, from just above the tropopause up to the thermosphere where molecular oxygen starts to be the strongest heating agent. As the ozone chemistry is rather complex in the stratosphere, a detailed chemistry scheme including heterogeneous processes is necessary to fully assess the coupling effects.

3-D-models of the middle atmosphere including a full stratospheric chemical module can be divided into two categories: first, within the framework of observations of trace gases in the stratosphere chemical transport models have been developed to analyze the specific observations and to study chemical processes in detail (Lefèvre et al., 1994; Chipperfield et al., 1995). These models take the meteorology from analyzed observations, for example analyses of the European Centre for Medium Range Weather Forecast (ECMWF), and therefore cannot study the influence of the chemistry on the dynamics. On the other hand, 3-D general circulation models (GCM) have been presented with the chemistry included into the model. In most of these GCMs the chemistry is not coupled to the dynamical 
part of the model. For example, Eckman et al. (1995) only included gas phase chemistry in their model, but Steil et al. (1998) also included heterogeneous chemistry, but the top level of their model is at $10 \mathrm{hPa}$. Rasch et al. (1995) have used their model in a partially coupled mode where predicted $\mathrm{H}_{2} \mathrm{O}$ was used as input of the dynamics. Austin et al. (1997) studied the influence of the vertical resolution on model results using a coupled version of their GCM but did not analyze the coupling effects. Zhao et al. (1996) made a detailed comparison of the effects of an ozone perturbation by sulphate aerosols in a coupled GCM up to $33 \mathrm{~km}$ altitude but did not discuss the meteorology and chemistry of their model in general.

On the other hand, some investigations of radiative forcing effects and the ozone hole (see World Meteorological Organization, WMO, 1994) included results for the ozone sensitivity in the stratosphere. For example, Schoeberl and Strobel (1978), and Ramanathan and Dickinson (1979) used simplified 2-D-models, Fels et al. (1980), Kiehl and Boville (1988) and Christiansen et al. (1997) used GCMs to test the response of the atmosphere to prescribed changes of the ozone concentration. Generally, the results of these experiments show the strongest influence of ozone changes in the upper stratosphere and reflect the change in the heating rates. These studies also revealed limitations of the often used fixed dynamic heating approximation (see Ramanathan and Dickinson, 1979) in estimating the influences of ozone depletion on the state of the atmosphere. To test the influence of different ozone climatologies, Langematz et al. (1997) performed multiyear experiments with their GCM and found an influence on the model results which is of a similar order of magnitude as that found in the heavy ozone depletion $(50 \%)$ experiments.

When coupling the chemistry to the dynamics in the model through ozone, feedback mechanisms are incorporated into the system. The general trend of this feedback should be stabilizing: for example, the higher temperature caused by an increase of ozone and the resulting stronger solar heating will increase the destruction of ozone due to the temperature dependence of the reaction kinetics. This well-known negative correlation of temperature and ozone has an observed maximum in the tropical upper stratosphere at about $2 \mathrm{hPa}$ (see for example Brasseur and Solomon, 1986) and was included theoretically into one-dimensional or box model calculations (see, e.g. Luther et al., 1977; Froidevaux et al., 1989). Christiansen et al. (1997) only mention a weak feedback effect in their model using a simplified chemistry which has a maximum at $10 \mathrm{hPa}$.

In this work results of the Karlsruhe simulation model of the middle atmosphere (KASIMA) are presented. A detailed chemistry scheme for the stratosphere was included into the model. The model can be run in a coupled mode where the ozone field used for determining the heating rate is taken from the chemistry module. First it is demonstrated that the uncoupled version of the model is able to simulate the meteorology and chemistry of the stratosphere realistically. Then, the influence of the ozone field from the chemistry module on the outcome of the model is investigated with the predicted ozone being coupled to the dynamics. In addition we tried to isolate the major mechanisms which cause the differences between the model versions and settle the question of how strong the effects which result from coupling and not just from changing the ozone field are.

\section{Model description}

\subsection{Meteorology}

KASIMA is a mechanistic model of the middle atmosphere which can be coupled to specific meteorological situations by using analyzed lower boundary conditions. The model is based on the solution of the primitive meteorological equations formulated in spectral form with $z=-H \log \left(p / p_{0}\right)$, where $H=7 \mathrm{~km}$ and $p_{0}=1013 \mathrm{hPa}$, as the vertical coordinate at equidistant levels. The resolution is variable in all three dimensions, as are the altitudes of the upper and lower model boundary. The model was previously used for a general discussion of the dynamics of the middle atmosphere (Kouker, 1993) and for a study of downward transport of mesospheric air into the upper stratosphere (Kouker et al., 1995). In the present version at the lower boundary the model is driven by the geopotential and temperature fields given by ECMWF analyses. The effects of breaking gravity waves are included using an implementation of the model of Lindzen (1981).

Chemical substances and inert tracers are transported according to the flux-corrected transport algorithm of Boris and Book (1973) applying the limiter function of Roe and Baines (1982). The advection scheme is positive definite and conserves first and second momentum. It is also 'total variation diminishing' and thereby minimizes spurious oscillations. The scheme is applied within the model using operator splitting. More details of the model can be found in Kouker (1995).

\subsection{Radiation}

In the standard, uncoupled mode the ozone concentration for determination of the heating rates is taken from the climatology of CIRA (Rees et al., 1990) in an updated version by Fortuin and Langematz (1994). For water vapour the 2-D water vapour climatology given by Chiou et al. (1997) has been used.

Solar heating rates are determined using the formalism of Strobel (1978) for $\mathrm{O}_{2}$ and $\mathrm{O}_{3}$ and the parametrization of Freidenreich and Ramaswamy (1993) for $\mathrm{CO}_{2}$ and $\mathrm{H}_{2} \mathrm{O}$. The $\mathrm{CO}_{2}$ cooling rate including NLTE effects above $70 \mathrm{~km}$ is determined using the parametrization of Fomichev et al. (1993), whilst for $\mathrm{O}_{3}$ cooling rates the parametrization of Fomichev and Shved (1985) has been implemented. For water vapour the cooling-tospace approximation of $\mathrm{Zhu}(1994)$ is used. The $\mathrm{CO}_{2}$ cooling rate in the NLTE case critically depends on the collision coefficient with atomic oxygen, a value of $5 \cdot 10^{7} \mathrm{~s}^{-1} \mathrm{~atm}^{-1}$ is adopted. 


\subsection{Chemistry}

The chemical scheme included in KASIMA is used up to an altitude of $70 \mathrm{~km}$ and comprises the gas phase reactions of the oxygen species $\left(\mathrm{O}_{\mathrm{x}}=\mathrm{O}_{3}+\mathrm{O}\left({ }^{1} \mathrm{D}\right)+\right.$ $\left.\mathrm{O}\left({ }^{3} \mathrm{P}\right)\right)$, the hydrogen species $\left(\mathrm{H}_{2} \mathrm{O}, \quad \mathrm{H}_{2} \mathrm{O}_{2}\right.$, $\left.\mathrm{HO}_{\mathrm{x}}=\mathrm{H}+\mathrm{OH}+\mathrm{HO}_{2}\right)$, the nitrogen species $\left(\mathrm{N}_{2} \mathrm{O}_{5}\right.$, $\mathrm{HONO}, \mathrm{HNO}_{3}, \mathrm{HO}_{2} \mathrm{NO}_{2}, \mathrm{~N}_{2} \mathrm{O}, \mathrm{NO}_{\mathrm{x}}=\mathrm{N}+\mathrm{NO}+$ $\left.\mathrm{NO}_{2}+\mathrm{NO}_{3}\right)$, the chlorine species $\left(\mathrm{Cl}_{2}, \mathrm{OClO}, \mathrm{HCl}\right.$, $\mathrm{HOCl}, \mathrm{ClNO}_{2}, \mathrm{ClONO}_{2}, \mathrm{ClO}_{\mathrm{x}}=\mathrm{Cl}+\mathrm{ClO}+\mathrm{Cl}_{2} \mathrm{O}_{2}$ ), the bromine species $\left(\mathrm{BrCl}, \mathrm{HBr}, \mathrm{HOBr}, \mathrm{BrONO}_{2}\right.$, $\mathrm{BrO}_{\mathrm{x}}=\mathrm{Br}+\mathrm{BrO}$ ) and the oxidation of methane.

The gas phase reaction scheme consists of $101 \mathrm{bi}$ - or termolecular reactions, 39 photodissociations and 10 heterogeneous reactions on liquid aerosols, nitric acid trihydrate (NAT), and ice. The reaction rates are taken from the compilation of DeMore et al. (1997). The photodissociation coefficients are interpolated from values in a reference table. The photodissociation coefficients in this table are calculated using the photon flux model of Röth (1992) and depend on the height, the zenith angle and the ozone column. The heterogeneous processes on polar stratospheric clouds (PSC) are calculated using the conventional scheme which was proposed by Poole and McCormick (1988). To make predictions as to when the occurrence of PSCs is thermodynamically possible, the algorithm given in the paper of Hanson and Mauersberger (1988) is used. Herein, the existence of NAT and ice depends on the temperature, the $\mathrm{HNO}_{3}$ mixing ratio and the water vapour pressure. The reaction rate on PSCs is calculated as a function of the radius of these particles assuming a constant concentration of 1 particle NAT per $\mathrm{cm}^{3}$ and 0.01 particle ice per $\mathrm{cm}^{3}$ (Drdla and Turco, 1991). The sedimentation of NAT and ice is calculated as a function of the radius of the particles (Müller and Peter, 1992). The heterogeneous scheme on liquid sulphuric acid aerosols is taken from Carslaw et al. (1995). It is assumed that sulphuric aerosols remain liquid until the ice point. The chemical species are divided into species with long chemical lifetimes (such as $\mathrm{N}_{2} \mathrm{O}, \mathrm{CH}_{4}$ and $\mathrm{HCl}$ ) and species with short chemical lifetimes (such as $\mathrm{OH}$ and $\mathrm{O}\left({ }^{3} \mathrm{P}\right)$ ). The short-lived species are grouped into families. These families are transported together with the long-lived species. The chemical concentrations of the transported species are calculated via an iterative Euler Backward solution. The analytical solution of the chemical differential equation is used to calculate the concentrations of the nontransported species. The chemical species are initialised

Table 1. Performed experiments

\begin{tabular}{|c|c|c|}
\hline Number & Mode & Description \\
\hline R1 & Uncoupled & Ozone from climatology \\
\hline $\mathrm{R} 2$ & Coupled & Ozone on-line from chemistry module \\
\hline $\mathrm{R} 3$ & Uncoupled & $\begin{array}{l}\text { Ozone as zonal monthly mean } \\
\text { values of } \mathrm{R} 1\end{array}$ \\
\hline R4 & Uncoupled & $\begin{array}{l}\text { Ozone as zonal monthly mean } \\
\text { values of } \mathrm{R} 2\end{array}$ \\
\hline
\end{tabular}

by using model data of the 2-D model of the Max Planck Institute for Chemistry (Grooß, 1996) as are the source gas distributions of CFC's and $\mathrm{CH}_{3} \mathrm{Br}$. For transport through the lower boundary and the maximum level of the chemical scheme into the domain of the chemical module a zero vertical gradient of the mixing ratios is assumed. The aerosol content is taken from Thomason et al. (1997).

\subsection{Experiments}

The Northern Hemisphere winter period 1992/93 is used for the simulation. The meteorological data at the lower boundary have been taken from the ECMWF analyses.

The model version used for these runs extends from $10 \mathrm{~km}$ to $120 \mathrm{~km}$ with 63 equally spaced layers yielding a vertical resolution of about $1.7 \mathrm{~km}$. The triangular truncation T21 corresponds to about $5.6^{\circ} \times 5.6^{\circ}$. A time step of $15 \mathrm{~min}$ is used for the dynamical and chemical part, the radiation is recalculated after every third timestep.

In total, four runs have been performed. Table 1 summarizes their different properties. In the following sections the expression off-line ozone is used for climatological ozone distributions, on-line ozone for ozone fields taken from the chemistry modules, uncoupled run for the standard case where heating rates are determined using the ozone climatology, and the expression coupled run will be used when the on-line ozone field is used. In the coupled runs above $70 \mathrm{~km}$ the ozone climatology is used with no transition region. No other changes were made in the model.

All runs start on July 4, 1992, and run for 10 model months. For most of the comparisons we selected December conditions. After three months of integration model conditions are reached which are independent of the model startup and an equinoctial and half a solstitial period is then modelled. In addition also results for Northern Hemisphere meteorology in late spring are shown.

\section{The middle atmosphere of the model in the uncoupled case}

The model is first characterized with results of the uncoupled run (R1) which also represents the standard version. At first zonal mean temperature results are compared with climatological data for the whole altitude range of the model and with analyses and observations which are available for lower altitudes only. Fields of EPV (Ertels Potential Vorticity) and the velocity stream function are shown in comparison with analyses of December and late spring, the chemistry and transport in the model are exemplified with ozone, $\mathrm{N}_{2} \mathrm{O}$, and $\mathrm{HNO}_{3}$ distributions for December.

\subsection{Dynamics: temperature and zonal wind}

Figure 1 shows the December monthly means for the zonal mean temperature and zonal wind, Fig. 2 the same 

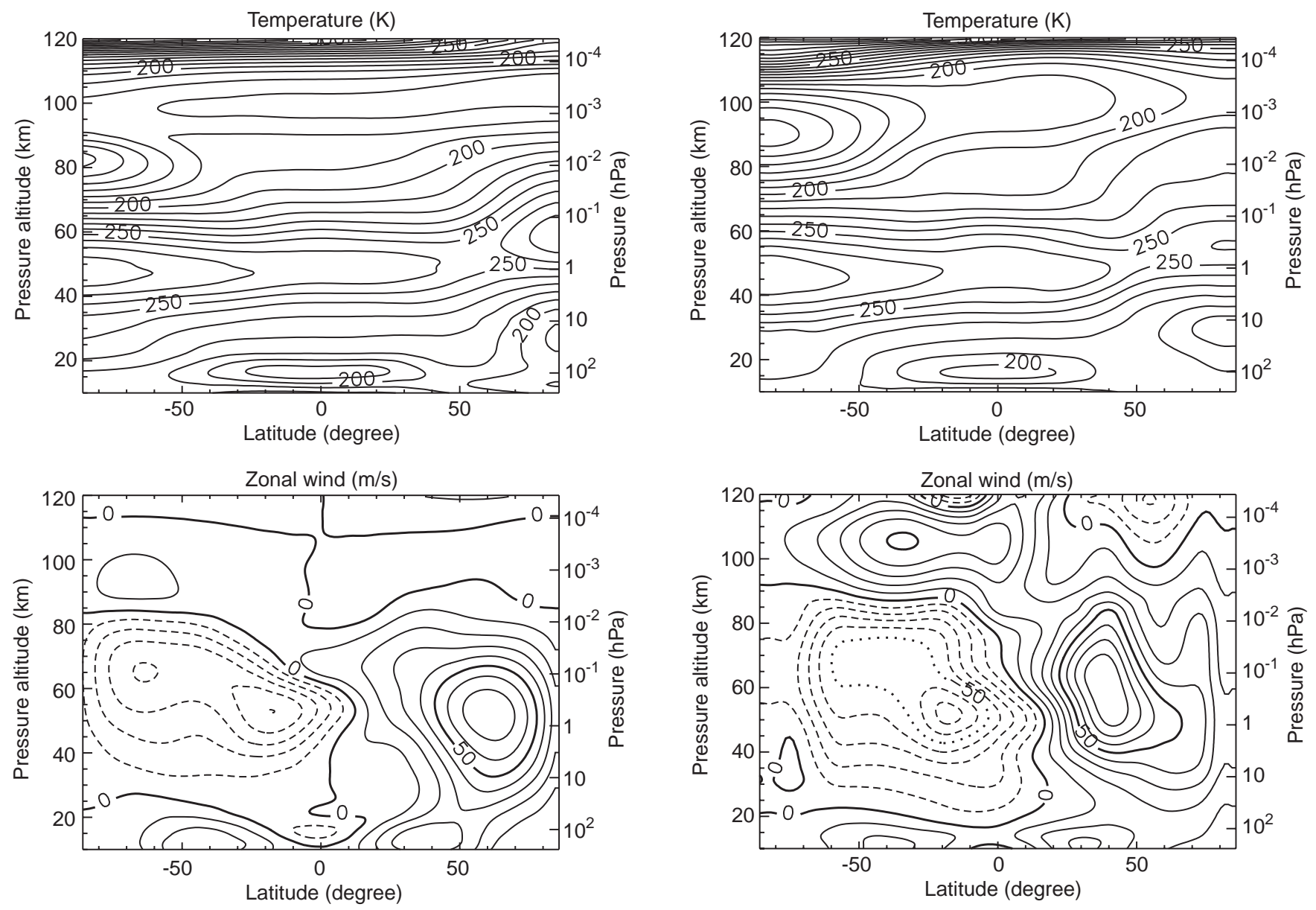

Fig. 1. Zonal mean temperature and zonal wind for December of the uncoupled run (R1). Contour intervels are $10 \mathrm{~K}$ and $10 \mathrm{~m} / \mathrm{s}$, dashed lines show negative values

for the CIRA86 climatology (Rees et al., 1990). In Fig. 3 the zonal mean temperature is compared with the climatology for December and with observations of the Cryogenic Limb Array Etalon Spectrometer (CLAES) aboard the Upper Atmosphere Research Satellite (UARS) (Gille et al., 1996) and ECMWF analyses for December 30, 1992.

The model simulation gives the general picture of the middle atmosphere: cold lower stratosphere, warm stratopause, cold summer mesopause. In terms of strength and location both stratospheric jets are presented well by the model as compared to the CIRA climatology (Fig. 2). The wind reversal at the mesopause is present in both hemispheres. Deficits to note in comparison with the climatology: the upper mesosphere and lower thermosphere are too cold, the summer mesopause is not high enough, the northern polar stratopause is too warm, a cold bias of about $5-10 \mathrm{~K}$ is observed in the summer hemisphere beneath the stratopause. A cold stratospheric bias and higher deviations from the climatology in the polar winter stratopause can often be found in models (see e.g. Manzini and Bengtsson, 1996; Boville, 1995; Langematz and Pawson, 1997) and are of same order of magnitude as seen in this model.

Fig. 2. Zonal mean temperature and zonal wind of the CIRA climatology for December, contour intervals as Fig. 1

Much too low temperatures are observed two layers above the lower boundary. This is most obvious in northern high latitudes. Such a cold bias in this altitude is also seen in some GCMs (see earlier references, and also Hurrell, 1995, who discuss this aspect in more detail).

Now the model is compared with observations and analyses for Dec 30, 1992 of CLAES and ECMWF respectively. Only CLAES data north of $-30^{\circ}$ are available for that date, see Fig. 3 centre. The CLAES observations are most reliable between 15 and $55 \mathrm{~km}$. Generally, the comparison with CLAES is quite similar to the comparison with the climatology: a general cold bias in the stratosphere and a warmer region in the stratosphere at midlatitudes is observed. Maximum differences of $+12 \mathrm{~K}$ and $-10 \mathrm{~K}$ are found at the polar stratopause and at the tropical tropopause, respectively. The differences in the altitude range of 30 to $40 \mathrm{~km}$ are reduced and partly reversed in the tropics compared with the climatology. The comparison with ECMWF analyses reveals in more detail the cold bias in the lower stratosphere with generally $10-15 \mathrm{~K}$ at $15 \mathrm{~km}$ and a maximum deviation of $-20 \mathrm{~K}$ just above the lower boundary. In the southern polar lower stratosphere the ECMWF analyses show lower temperatures than the climatology. Hemispheric plots of temperature of 

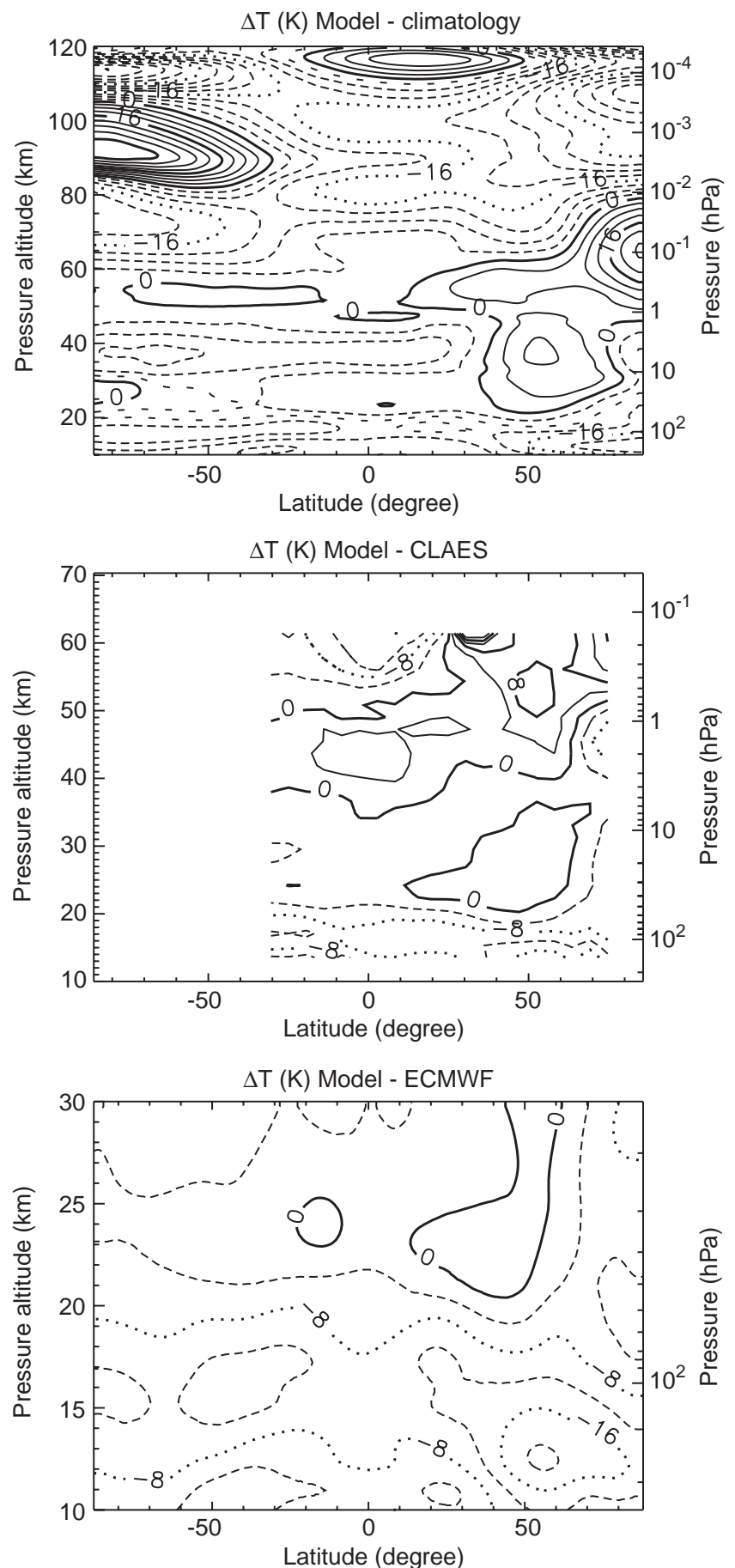

Fig. 3. Zonal mean difference of temperature of model - climatology (December monthly mean) (top), model - CLAES data (centre) and model - ECMWF data (bottom) for 30 December, 1992. Contour interval $4 \mathrm{~K}$. (note different altitude ranges)

ECMWF analyses and the model are shown in Fig. 4 for the Northern Hemisphere. The amplitude of the spatial temperature variation is higher in the model than in the analyses. There is a colder region in the vortex with a maximum difference of $12 \mathrm{~K}$ as compared to the analyses.

\subsection{Dynamics: EPV and velocity stream function}

Results for the dynamics are further exemplified by comparison of EPV and velocity stream function fields under northern hemispheric mid winter conditions and in northern hemispheric spring when the polar vortex breaks down, see Figs. 5 and 6 . For both dates a sufficient agreement between model and observations is found. Differences to note: on December 30, the model cannot reproduce the plateau of EPV values seen in the analyses and, thus, it does not exhibit the strong gradient to midlatitudes. Maximum EPV values occur in the western hemisphere and generally higher EPV values are reached in the model. A small phase shift to the east is observed in the overall form of the vortex. The velocity stream function behaves quite similarly. On April 14, 1993, (see Fig. 6) higher EPV values are observed for the model, too. The vortex is now closer to the pole as compared to the analyses. The general structures of EPV and the velocity stream function are similar again.

\subsection{Transport and chemistry: ozone, $\mathrm{N}_{2} \mathrm{O}$ and $\mathrm{HNO}_{3}$}

The ozone climatology for December together with the monthly mean ozone field of the chemistry module of run R1 is shown in Fig. 7. Data are only shown up to $70 \mathrm{~km}$ where the chemistry module is implemented. Both ozone fields look rather similar in their shapes and absolute values. The maximum value of the CIRA data is $9.6 \mathrm{ppmv}$, whereas the chemistry module gives values of up to 10.5 ppmv. The difference of the model and climatology ozone distributions (see Fig. 8) reveals lower ozone concentrations in the lower stratosphere, higher ozone values from about $25 \mathrm{~km}$ up to $38 \mathrm{~km}$ and an ozone deficit from $38 \mathrm{~km}$ up to about $60 \mathrm{~km}$. This last feature is often seen in stratospheric models which show ozone deficits in the range of $10-30 \%$ (see for example Siskind et al., 1995) whether the discrepancy is a real effect is under discussion (Crutzen et al., 1995). Between about 60 and $70 \mathrm{~km}$ the zonal mean ozone mixing ratio values are higher in the model than the climatological data.

In Fig. 9 hemispheric plots of the trace gases $\mathrm{N}_{2} \mathrm{O}$ and $\mathrm{HNO}_{3}$ are repesented for the model and CLAES data for December 30, 1992, at $26 \mathrm{hPa}$ (for CLAES data see Roche et al., 1993 for $\mathrm{N}_{2} \mathrm{O}$, and Kumer et al., 1996 for $\mathrm{HNO}_{3}$ ). The trace gas $\mathrm{N}_{2} \mathrm{O}$ may generally be considered an inert tracer demonstrating transport processes. Lower $\mathrm{N}_{2} \mathrm{O}$ model values within the vortex indicate a possibly too strong descent compared with the observations. The $\mathrm{N}_{2} \mathrm{O}$ data do not show any prominent phase shift which was found for the EPV fields. The two distinct maxima found in the observation are reproduced by the model. $\mathrm{HNO}_{3}$ exhibits stronger differences in the vortex region. As the model temperature inside the vortex falls partly below the ice point PSC formation and sedimentation is triggered, reducing the mixing ratio of $\mathrm{HNO}_{3}$ in the gas phase. The values in midlatitudes and the tropics are somewhat lower than observed. 
Temperature $(\mathrm{K})$

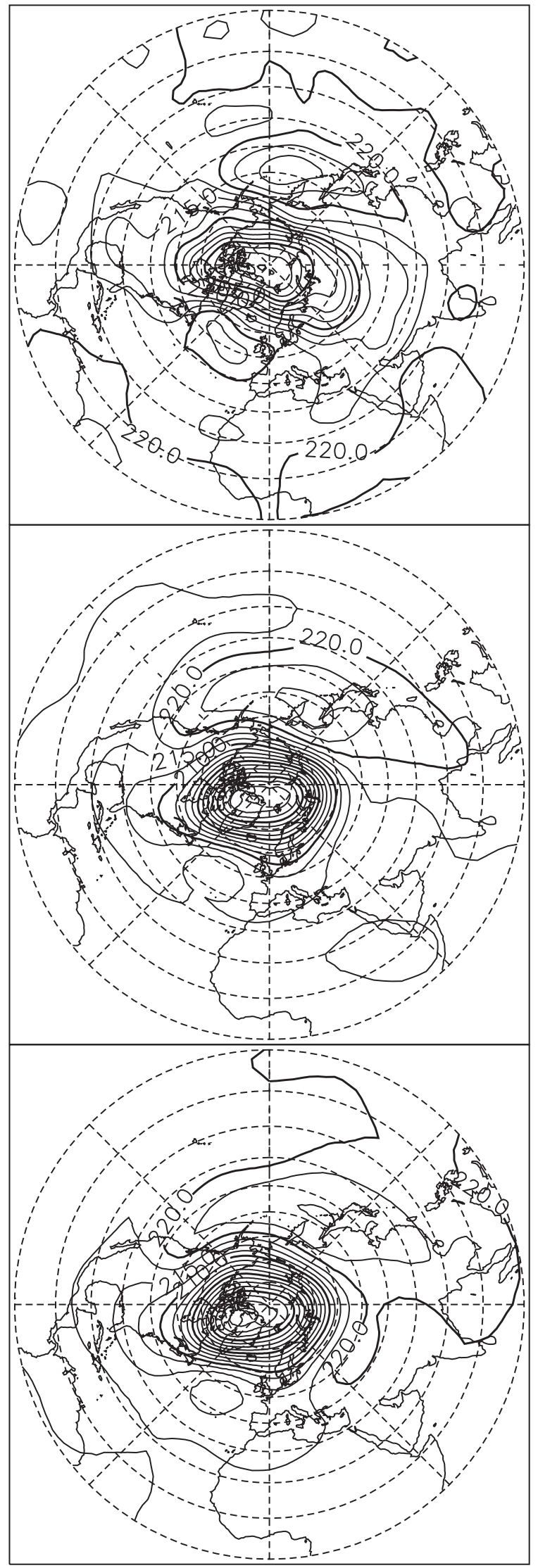

Fig. 4. Synoptic northern hemispheric plot of ECMWF temperatures at $26 \mathrm{hPa}$ (top), uncoupled version R1 (centre), and coupled version R2 (bottom) for December 30, 1992. Contour interval $2.5 \mathrm{~K}$

\section{Results in the coupled mode}

The discussion of the uncoupled mode demonstrates that compared with other 3-D-models of the atmosphere the model is in acceptable agreement with the observations in terms of the dynamics and the ozone distribution. The output in the coupled mode is discussed next. Using the coupled mode, no instabilities were introduced which might have been expected if there were positive feedback effects.

\subsection{Dynamics}

Figure 10 shows the zonal mean temperature of the coupled run (R2) and the difference to the uncoupled run for December. Below the stratopause the differences between the two models are less than $5 \mathrm{~K}$. A temperature increase of about $2.5 \mathrm{~K}$ is found in the tropical stratosphere and in the southern subarctic lower stratosphere. Above $40 \mathrm{~km}$ the temperature is lower by up to $15 \mathrm{~K}$ (maximum at $60 \mathrm{~km}$ in the summer hemisphere). This band with lower temperatures extends to the northern polar regions. The summer mesopause is shifted downwards by about $2 \mathrm{~km}$ yielding a temperature increase of about $10 \mathrm{~K}$ at $90 \mathrm{~km}$. Figure 11 shows the difference between the temperature of the coupled mode and the climatology. The cold bias in the stratosphere is stronger in the coupled version, but still comparable with other models (see discussion of uncoupled mode).

The zonal wind in the coupled version is shown in Fig. 12. Differences between both versions are most conspicuous in the northern polar stratosphere where the meridional temperature gradient and the vertical shear of the zonal wind are amplified.

At about $25 \mathrm{~km}$ altitude the zonal mean temperature differences are small. Analyzing the hemispheric plots of the uncoupled and coupled version (see Figs. 4, 5, 6, bottom row), the temperature amplitudes in the coupled version are found to be increased. Differences in PV and the velocity stream function between the analyses and model are more obvious in the coupled version than in the uncoupled version.

\subsection{Ozone}

The monthly mean of the zonal mean ozone field of the coupled run is shown in Fig. 13. The differences between on-line ozone of the uncoupled run and that of the coupled run are much smaller than between the on-line ozone of the uncoupled run R1 and the ozone climatology. When studying Figs. 13 and 8, the following behaviour is evident: where the on-line ozone in the uncoupled run shows higher values compared to the 


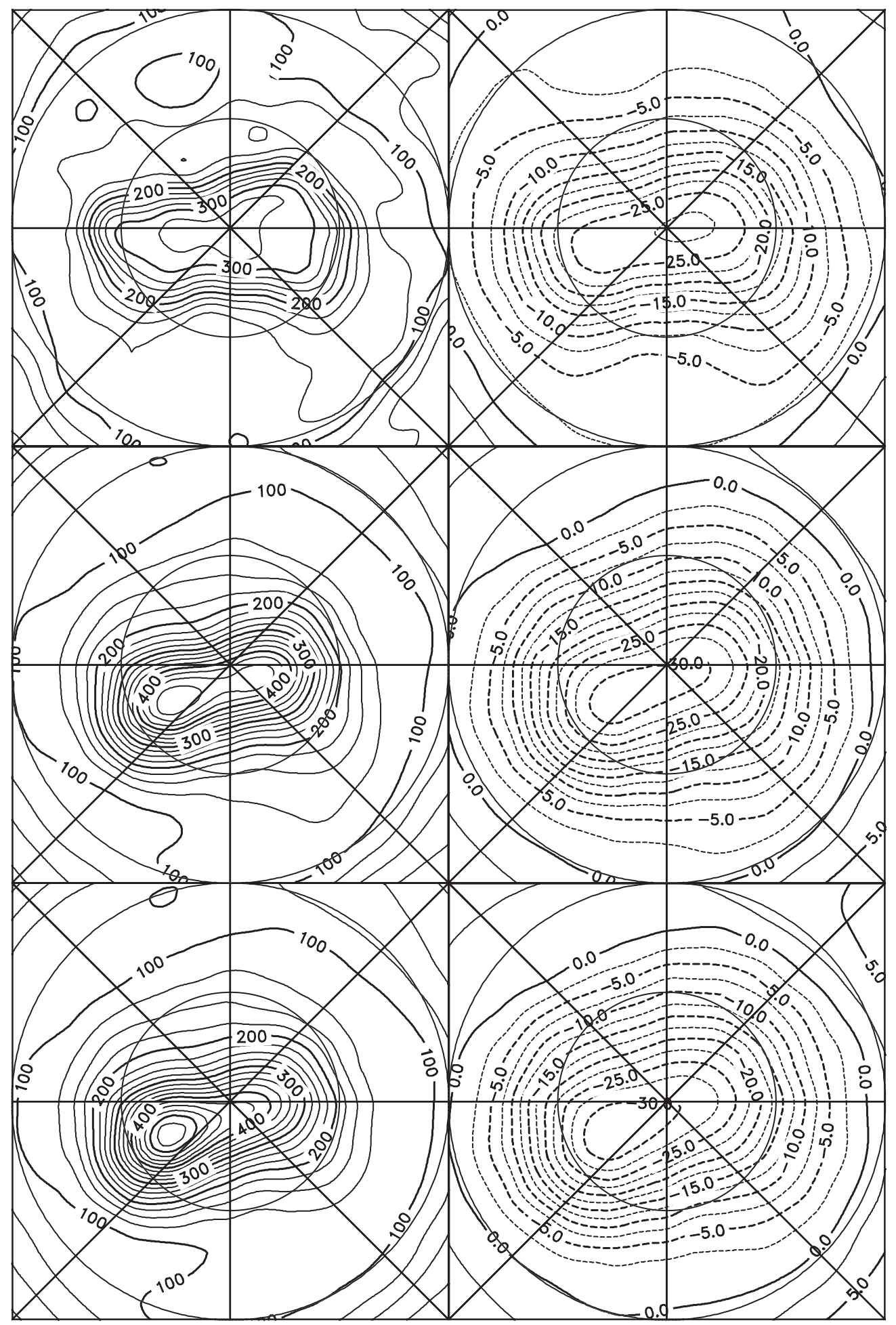

Fig. 5. Synoptic northern hemispherical plots of EPV (left) and the velocity stream function (right) for December 30, 1992 on the $640 \mathrm{~K}$ surface, with latitude circles at $30^{\circ}$ and $60^{\circ}$, along the Greenwich meridian. Top row: ECMWF data; centre: uncoupled model (R1); bottom: coupled model (R2) climatology, the coupled run exhibits a decrease (below about $40 \mathrm{~km}$ ) and where the uncoupled run shows a decrease (above $40 \mathrm{~km}$ ), the coupled run shows an increase. The ozone field of the coupled run is therefore closer to the climatology than the on-line field of the uncoupled run. In about $55 \mathrm{~km}$ altitude the ozone deficit which amounts to about $35 \%$ in the uncoupled run as compared to the climatology is reduced to about $25 \%$. The use of the coupled version is not sufficient to solve this mentioned ozone deficit problem, but may play an important role.

\section{Analyses of coupling effects}

First the variability of the temperature and ozone mixing ratio is analyzed within the month of December as an indication of the significance of the 


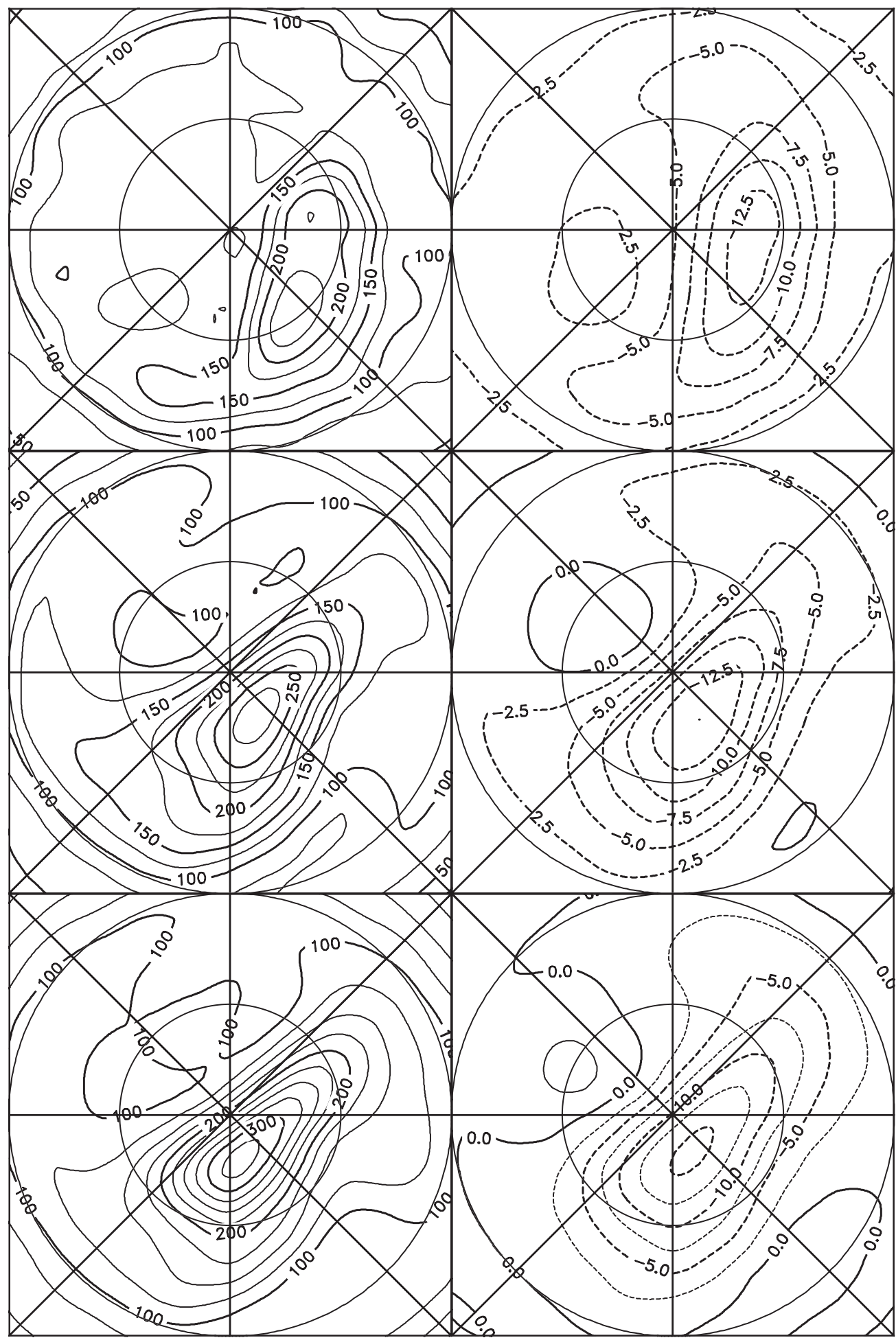

Fig. 6. Synoptic northern hemispherical plots of EPV (left) and the velocity stream function (right) for 14 April, 1993 on $640 \mathrm{~K}$ surface, orientation as in Fig. 5. Top row: ECMWF data; centre: uncoupled model (R1); bottom: coupled model (R2) differences between the runs R1 and R2. Figure 14 shows the variation of the zonal mean temperature and ozone for the uncoupled run, given as the standard deviation of the zonal mean values sampled at every time step over the month of December and corrected for a linear trend. Except for maxima in the winter polar region, the variation is below $2 \mathrm{~K}$. For ozone the variations over one month are found to be concentrated below $50 \mathrm{~km}$ and strongest in the polar regions. Most of the differences found between the coupled and uncoupled version of the model in sect. 4 are much higher and, hence, caused by the changes of the model versions. Now, we have tried to discriminate between the different possible mechanisms which cause the deviations between the coupled and uncoupled runs. 

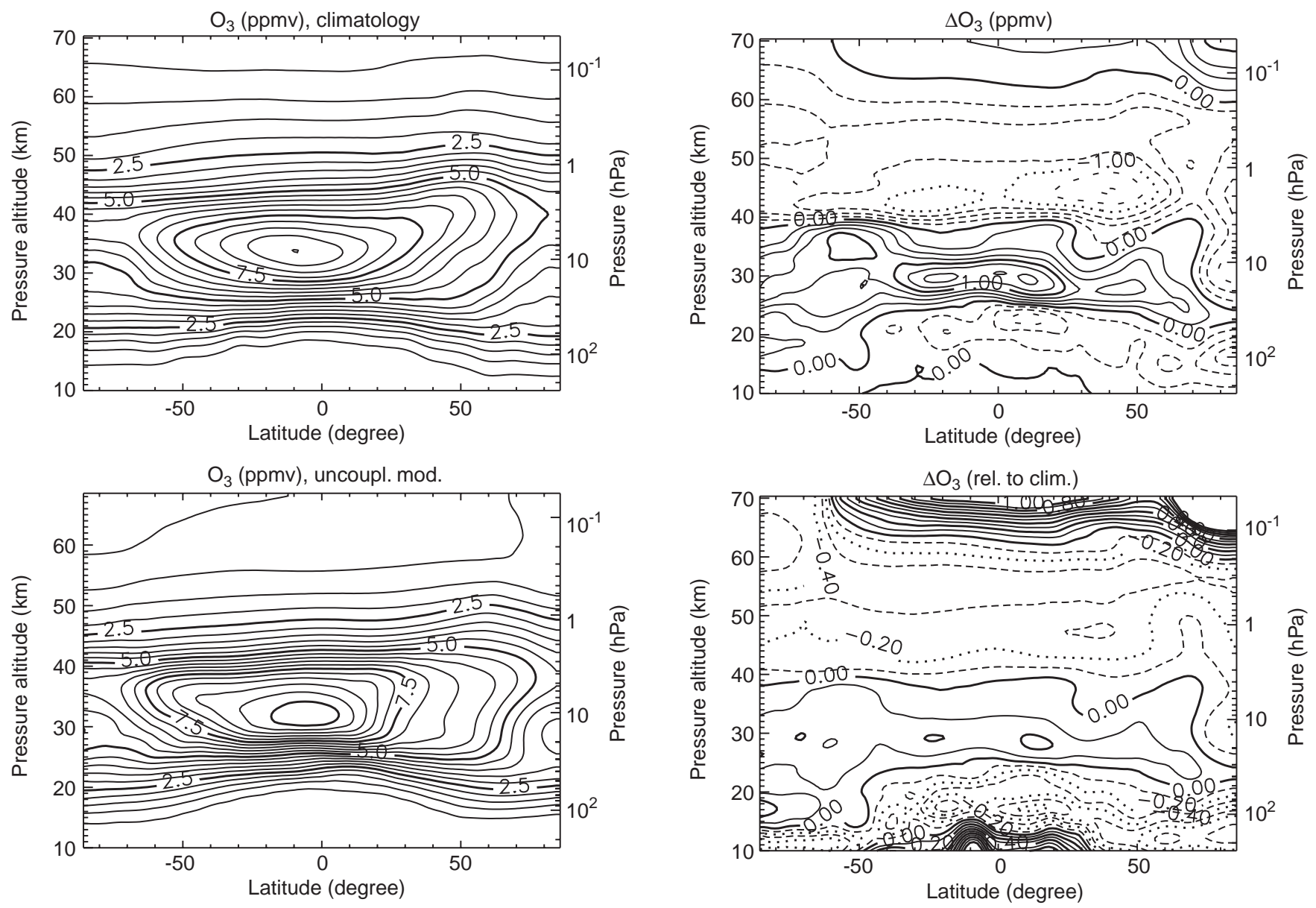

Fig. 7. December zonal mean values of ozone (ppmv). Top: climatology used; bottom: from the model chemistry in the uncoupled version (R1). Contour interval $0.5 \mathrm{ppmv}$

\subsection{Heating rates}

Most of the changes are expected to be caused by direct forcing of ozone (see Kiehl and Boville, 1988), that is by the difference of solar heating rates using the different ozone fields, the on-line and the off-line ozone. This already follows from the structure of the ozone deficit above $40 \mathrm{~km}$ (Fig. 8) which coincides with the structure of the temperature decrease (Fig. 10). Figure 15 gives the difference between the solar heating rates and the cooling rates in the case of the climatological ozone field and the on-line ozone up to $70 \mathrm{~km}$. Obviously most of the temperature change above $40 \mathrm{~km}$ stems from the change in solar heating rates. The cooling rates are much less important as ozone only contributes a minor portion to total cooling which is dominated by $\mathrm{CO}_{2}$, especially in the cooler part of the atmosphere. Below $40 \mathrm{~km}$ the correlation between the heating rate change and the temperature change is not obvious.

Above about $60 \mathrm{~km}$ in the zonal mean of the on-line ozone field, an increase is found as compared to the climatology (see Fig. 8), but no corresponding increase of the heating rates of Fig. 15. The reason for this discrepancy is the fact that when using on-line ozone for the determination of heating rates, the 3 -D-fields are

Fig. 8. December zonal mean of the difference of on-line ozone (R1) - climatology; top: absolute values in ppmv and (bottom): relative to climatology. Contour intervals 0.25 ppmv and 0.1

applied which exhibit more about $1 \mathrm{hPa}$ diurnal variations, as a photochemical equilibrium can be assumed at these altitudes (Brasseur and Solomon, 1986) and which have also been observed for satellite data (see e.g. Huang et al., 1997). During daylight, the photochemical equilibrium is shifted towards low ozone values and the heating rates are reduced, too. The higher ozone concentrations during night cannot influence the heating rates, of course. In the zonal mean of ozone of Fig. 8 an average of day and night values is given. Due to the day/night effect, the heating rates above $60 \mathrm{~km}$ are substantially lower than expected at first glance.

\subsection{Ozone-temperature feedback}

Besides direct forcing, the ozone field responds to the changed temperature. This is the well-known negative correlation between ozone and temperature (see e.g. Luther et al., 1977; Rees et al., 1990; Smith, 1995, and references herein) which peaks with a typical correlation of about $2 \%$ decrease in ozone for $1 \mathrm{~K}$ temperature increase at $2 \mathrm{hPa}$ in the equator region. In Fig. 16 the zonal and monthly mean temperature and ozone values are shown for three pressure levels $(8 \mathrm{hPa}, 2 \mathrm{hPa}$, 


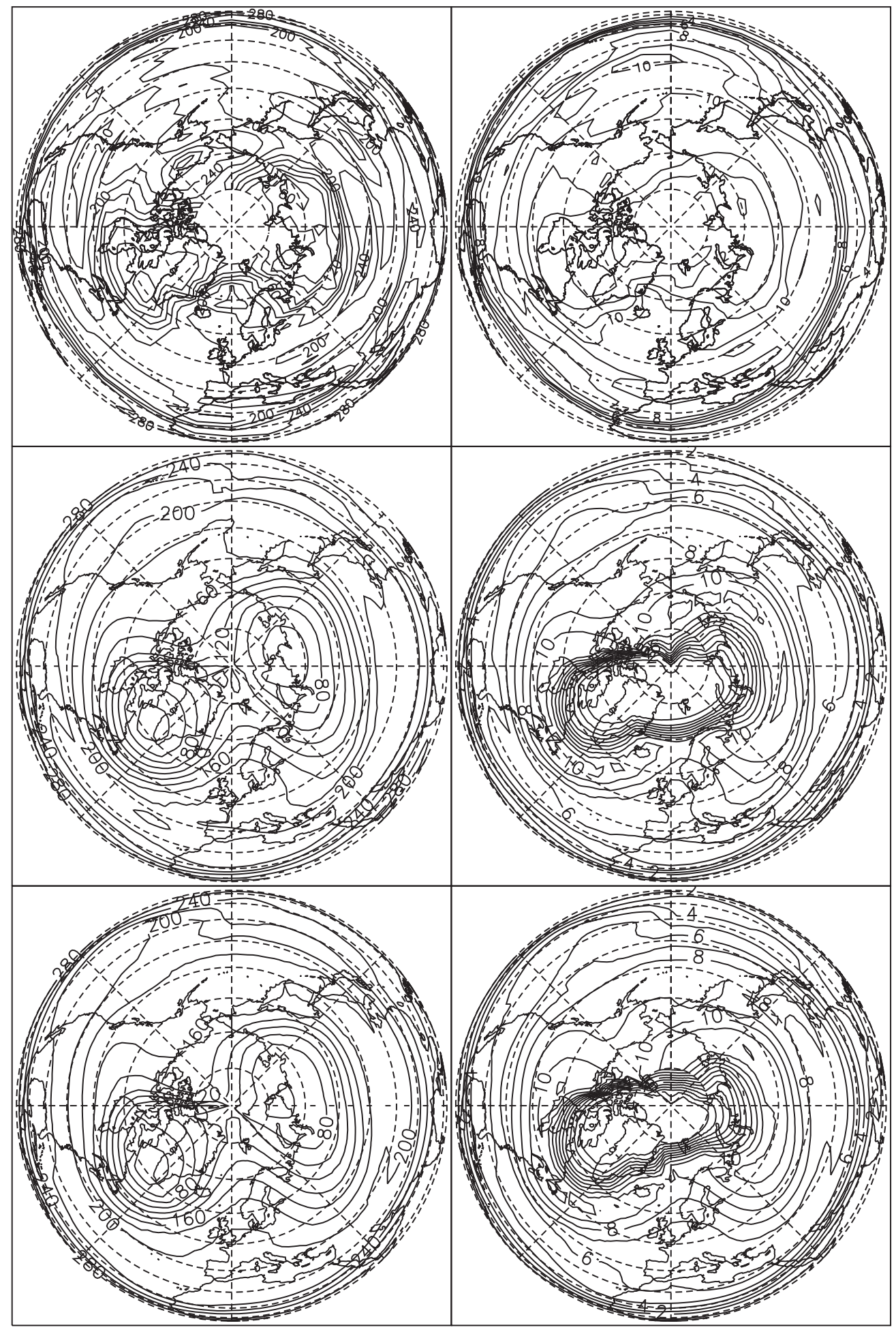

Fig. 9. Synoptic northern hemispherical plots of (left) $\mathrm{N}_{2} \mathrm{O}$ and (right) $\mathrm{HNO}_{3}$ for 30 December, 1992 at $26 \mathrm{hPa}$ in ppbV. Top: CLAES data; centre: uncoupled model (R1); bottom: coupled (R2)
$0.5 \mathrm{hPa}$ ) at the equator for the 10 months of simulation using the coupled version $\mathrm{R} 2$. Writing the correlation of the mixing ratio $f$ and the temperature $T$ in the form of $f=B \exp (\Theta / T)$ with $B$ and $\Theta$ as fit parameters, $\Theta$ values in the range of 400 and $1000 \mathrm{~K}$ can be determined with correlation coefficients $r$ between 0.5 and 0.8 in the pressure range of $8 \mathrm{hPa}$ and $0.5 \mathrm{hPa}$, see Fig. 17 where also the formal uncertainty for the fit parameter $\Theta$ is shown as an error bar. The correlation peaks at about 3
hPa with $\Theta=840 \mathrm{~K}$. Froidevaux et al. (1989) give the observed typical maximum values of $\Theta$ of about $1000 \mathrm{~K}$ at $2 \mathrm{hPa}$, with a similar dependency on height as found in our model. Comparing ozone and temperature for one specific date we find similar correlations, see Fig. 18. Here the day and night values have been marked differently to show the influence of the diurnal variation of the photolysis. During day, or during night, the negative correlation obviously also holds for $0.5 \mathrm{hPa}$, 

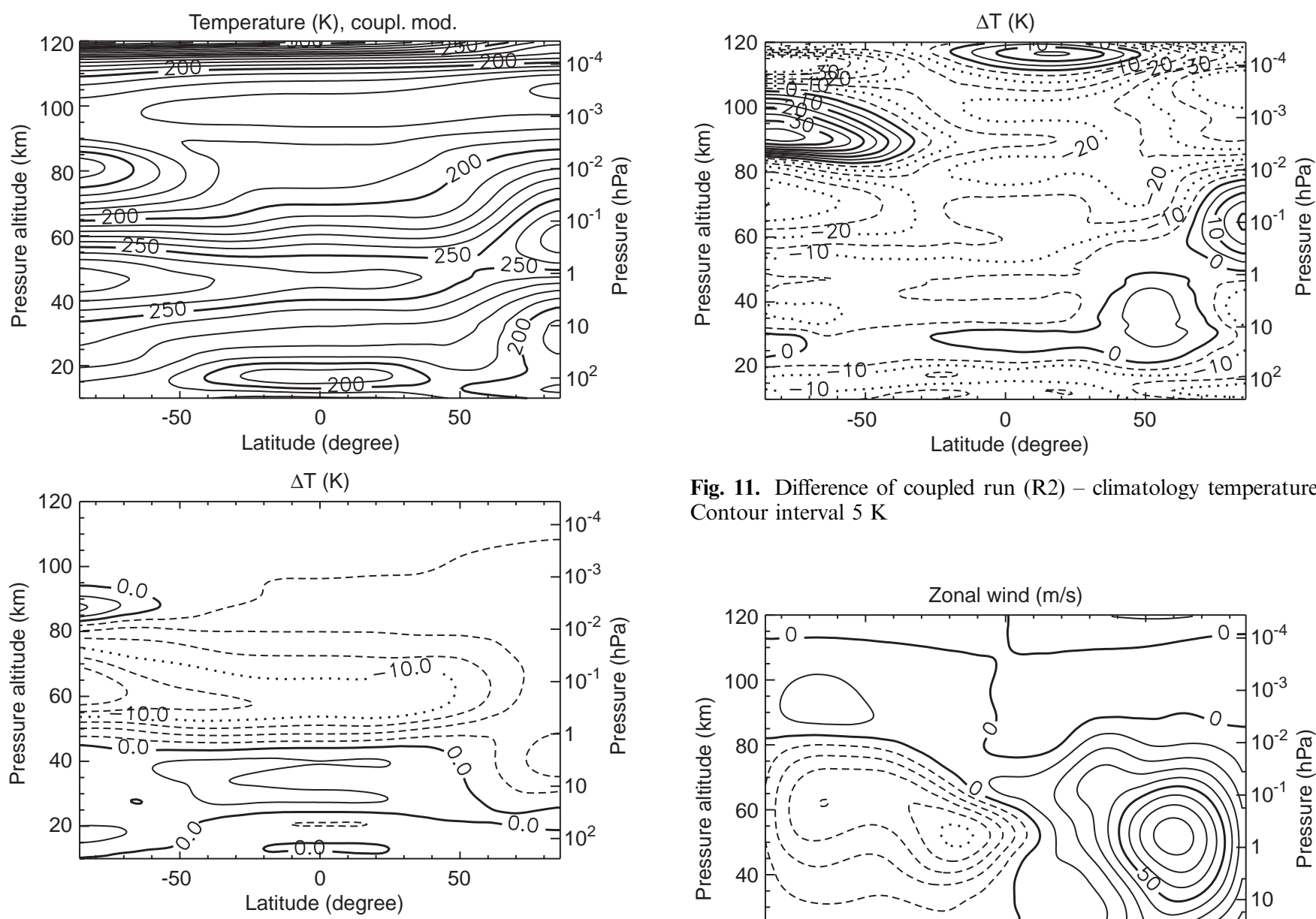

Fig. 11. Difference of coupled run (R2) - climatology temperature. Contour interval $5 \mathrm{~K}$

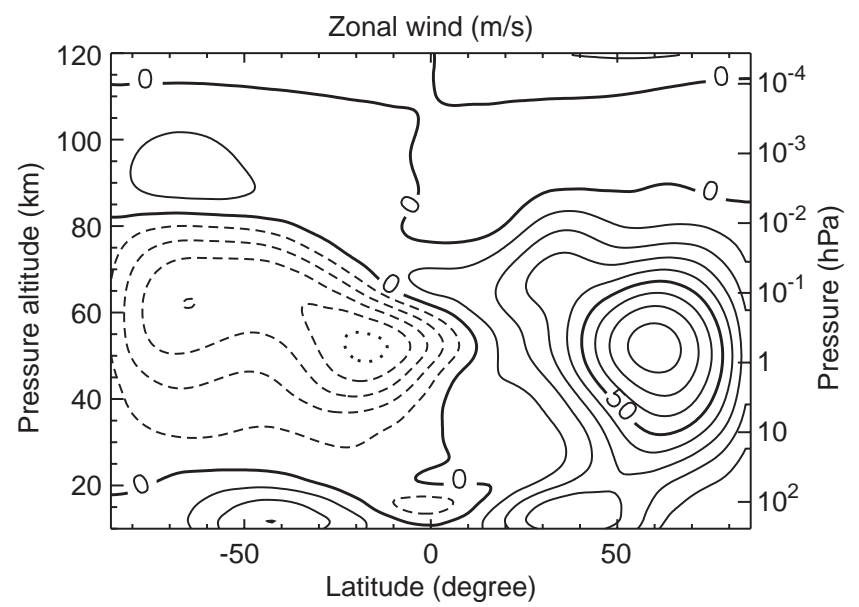

Fig. 10. December zonal mean values of the temperature in the coupled run and the difference of coupled (R2) - uncoupled (R1) run. Contour intervals $10 \mathrm{~K}$ and $2.5 \mathrm{~K}$

but not when using day and night data together. At $0.5 \mathrm{hPa}$ during the night the correlation is very close. At that height, the chemical lifetime of ozone is short as compared to the time scale of transport. Otherwise, transport would have destroyed this correlation based on reaction kinetics, so this tight correlation is to be expected. The correlation above $2 \mathrm{hPa}$ in the time series using data of the whole latitude circle is obviously lost in part by points at dusk or dawn, but transport effects cannot be excluded completely (see discussion of transport effects in Froidevaux et al., 1989). The correlation for one specific date is better compared with the work of Froidevaux et al. (1989): for $0.5 \mathrm{hPa}$ they found a value of $\Theta$ of about $1000 \mathrm{~K}$ and for $2 \mathrm{hPa}$ about $1400 \mathrm{~K}$, whereas for the specific date of December 30 , we obtained $611 \mathrm{~K}$ and $596 \mathrm{~K}$ respectively. With the scattering of the data at $2 \mathrm{hPa}$ the difference is within the uncertainty and also compatible with the zonal and monthly mean correlation.

\subsection{Using ozone from monthly mean values}

To study in further detail how the coupling affects the simulation two additional experiments have been per-

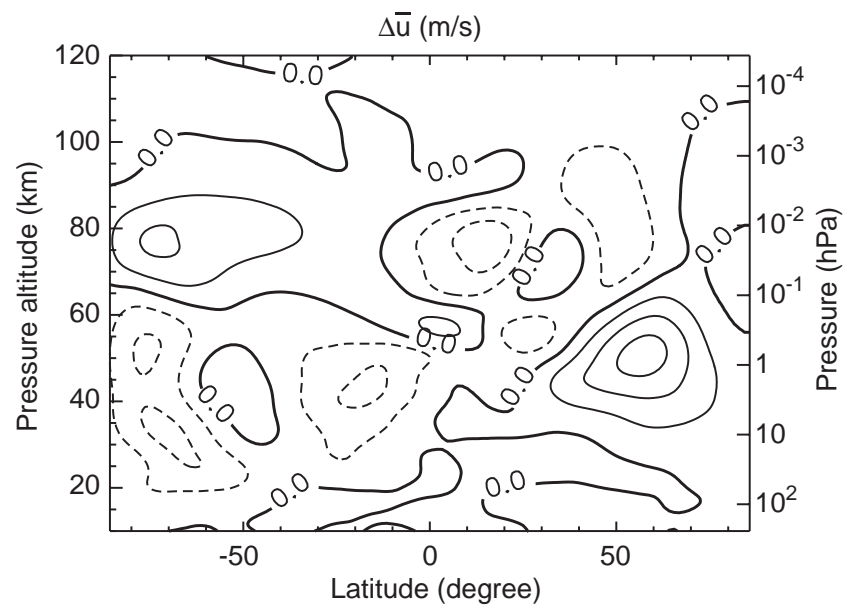

Fig. 12. December zonal mean values of the zonal wind in the coupled run (R2) and the difference of the coupled - uncoupled (R1) run. Contour interval distance $10 \mathrm{~m} / \mathrm{s}$ and $2.5 \mathrm{~m} / \mathrm{s}$

formed: run R3 uses on-line ozone values from the uncoupled run R1, and R4 the ozone data from the coupled run R2. These ozone distributions were used in the same way as the ozone climatology in the uncoupled run (R1), i.e. as monthly and zonal mean values. The 

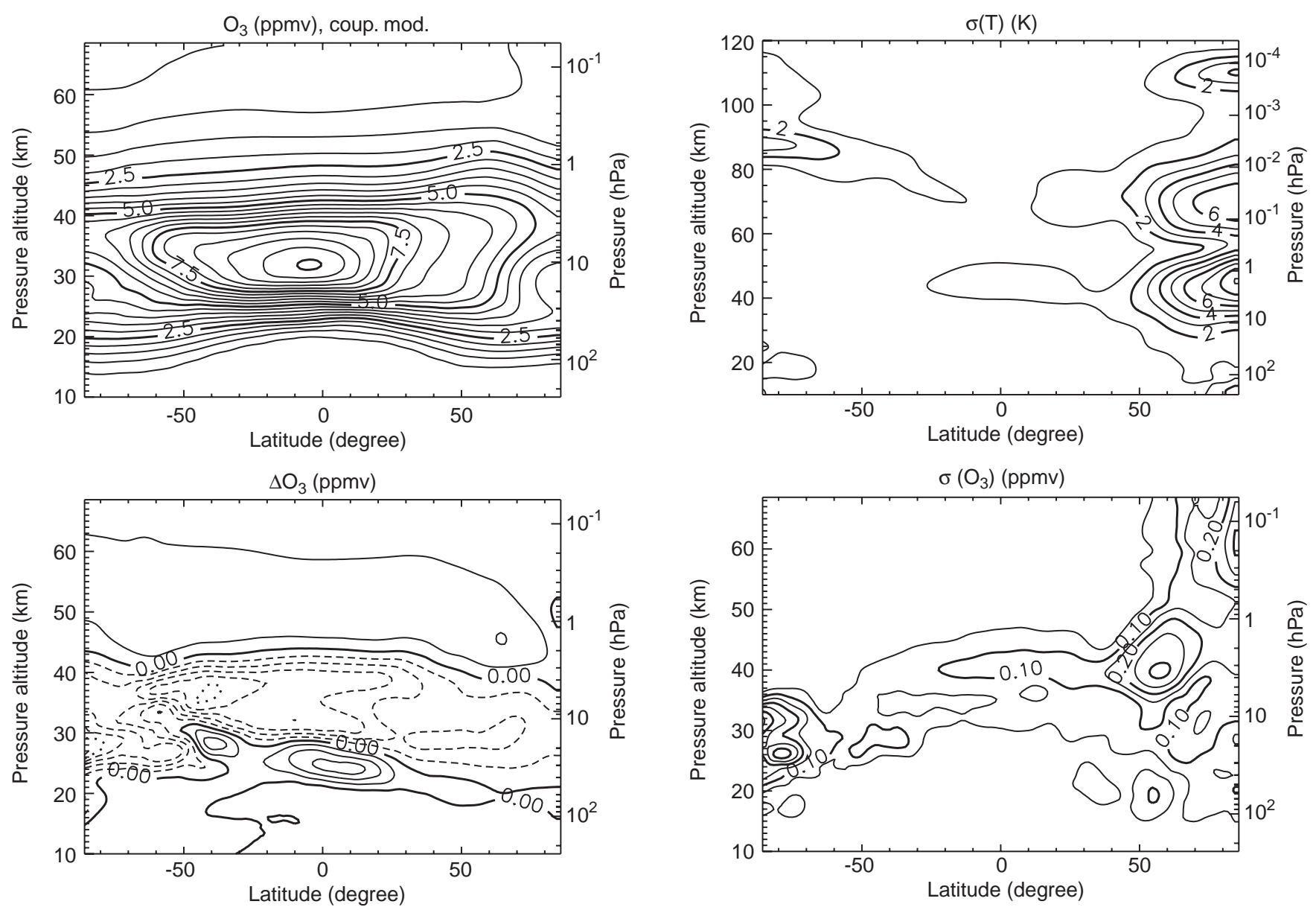

Fig. 13. December zonal mean values of ozone in the coupled run (R2) and the difference coupled - uncoupled (R1) on-line ozone. Contour intervals 0.5 and 0.1 ppmv

experiment R3 corresponds to an ozone perturbation experiment: how does the middle atmosphere respond when changing the ozone globally and how does it compare with the coupled version as a reference. This experiment lacks the chemical feedback effects already identified. In the second climatology the feedback is incorporated in the ozone distribution but only as a zonal and monthly mean. It serves as a test for finding out whether there are additional feedback mechanisms through chemistry and dynamics working in the time range of less than one month. This experiment was also intended to answer the question as to how usable ozone climatologies are for modelling the stratosphere.

The model has been run with these climatologies in the uncoupled mode. To correct for the day/night variation of ozone, the climatologies are constructed such that above $50 \mathrm{~km}$ height only the zonal mean and monthly mean daylight values are used. This height is a compromise between the neglecting of day/night effects and having a bias when using part of the data only, especially when dusk and dawn effects below $0.5 \mathrm{hPa}$ are to be avoided (see Fig. 18).

The result of the experiments using these climatologies is shown in Fig. 19. The first experiment yields a result that is expected: using the ozone concentration

Fig. 14. Zonal mean standard deviation of temperature and ozone for December corrected for linear trend (from R1). Contour intervals $1 \mathrm{~K}$ and 0.05 ppmv

without incorporating the feedback effects results in too high temperature changes, this can be seen when comparing Fig. 19 (top) with Fig. 10. This temperature difference is directly correlated with the difference of the ozone distributions R1 and R2 from which the heating rates are calculated, see Fig. 13. This experiment is quite similar to investigations of the radiativedynamical response of the atmosphere to changes in ozone, see again Kiehl and Boville (1988) and Christiansen et al. (1997). For a 50\% ozone reduction, they found a typical temperature response of minus 5-10 K throughout the stratosphere below about $40 \mathrm{~km}$ and up to $50 \mathrm{~km}$ a steep increase of this sensitivity. Normalizing the temperature response to the change of ozone in our experiment also yields the steep increase at $50 \mathrm{~km}$, and generally similar temperature reductions, but also a zone at about $40 \mathrm{~km}$ where the temperature reduction is small (not shown). That may suggest that non uniform ozone changes in a chemically coupled system behave differently than derived from simplified experiments.

The experiment R4 shows small differences of the zonal and monthly mean temperatures (Fig. 19 bottom) only as compared to experiment R2. In Fig. 20, the temperature difference of the run $\mathrm{R} 4$ and $\mathrm{R} 2$ is also 

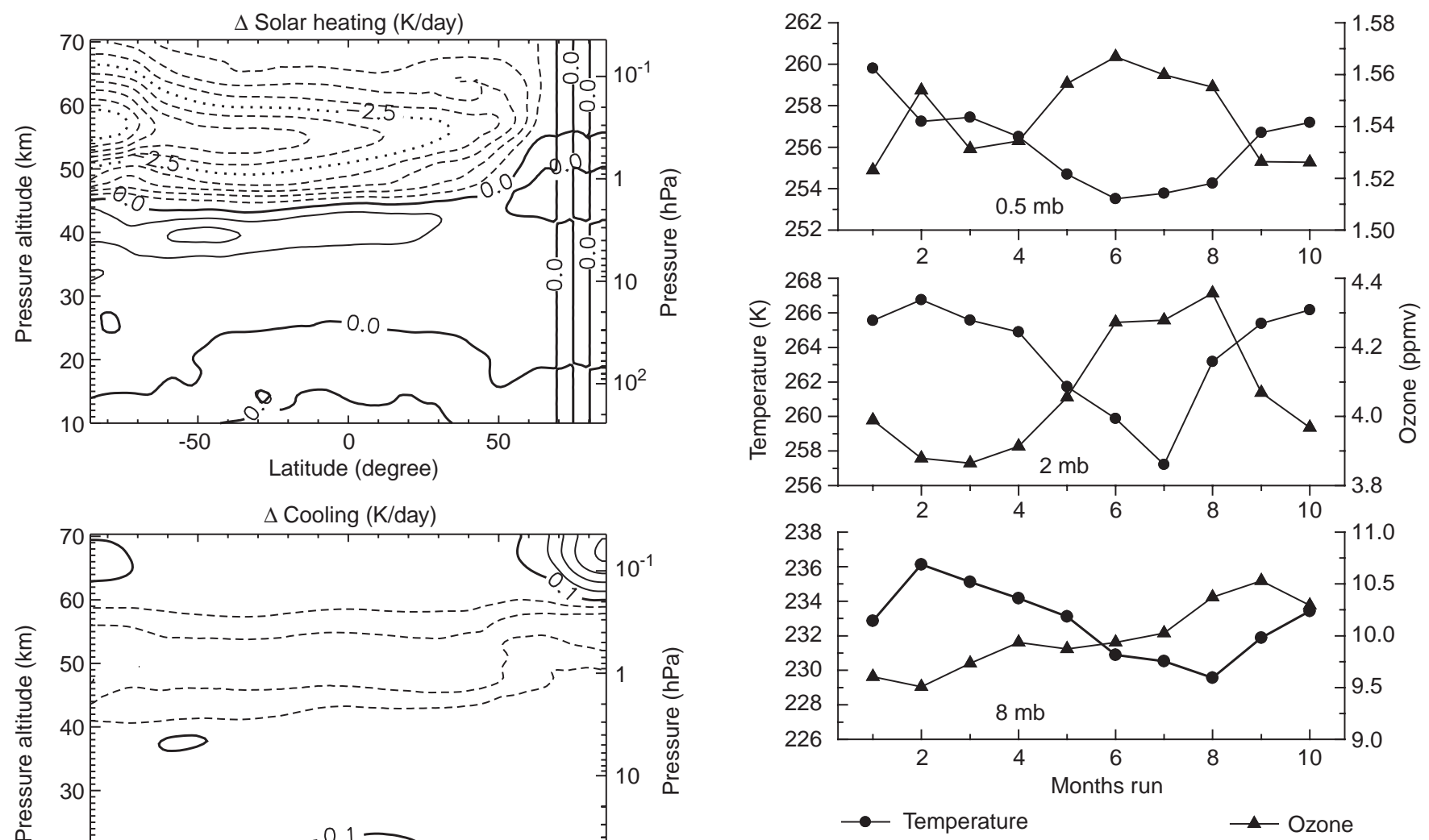

Fig. 16. Monthly and zonal mean values of temperature and ozone for 10 -month simulation at $0.5,2$ and $8 \mathrm{hPa}$ showing the anticorrelation of temperature and ozone

Fig. 15. December zonal mean values of the difference of solar heating rates (top) and cooling rates (bottom) in $\mathrm{K} /$ day (on-line ozone minus ozone climatology). Contour intervals $0.5 \mathrm{~K} /$ day and $0.2 \mathrm{~K} /$ day

shown at $2 \mathrm{hPa}$, again for December 30, 1992. The differences between the models are less than $1 \mathrm{~K}$. As at that height the feedback effects are strongest (see earlier) stronger feedback effects at that height and higher deviations are expected if the dynamics of the model using the climatology does not fit the coupled version. We therefore conclude that for undisturbed ozone conditions (no polar ozone hole) a realistic ozone climatology is sufficient for model simulations.

\section{Conclusions}

The studies with a dynamically chemically coupled model of the middle atmosphere have shown that the uncoupled and coupled version is able to simulate the middle atmosphere satisfactorily. The chemical module simulates a realistic ozone field. No instability of the model was observed. The model will serve as a basis for further process studies.

The detailed study of differences between the coupled and uncoupled version of the model showed that the direct forcing of ozone is responsible for most of the differences of the two model outputs. Despite the fact

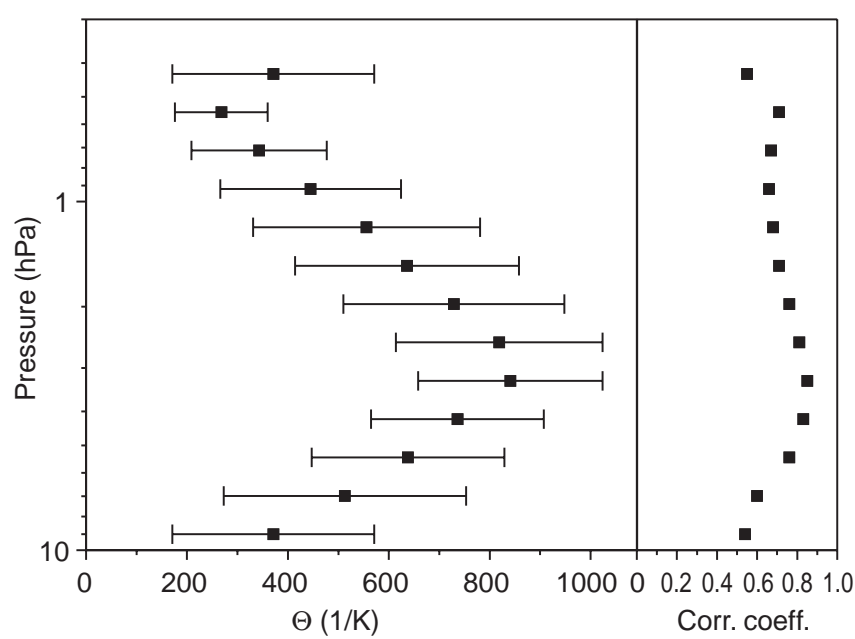

Fig. 17. Height dependence of the ozone temperature correlation expressed by the fit parameter $\Theta$ (see text). Error bars indicate formal uncertainty. Correlation coefficient is shown at right

that the negative temperature ozone correlation is well reproduced in the model, the feedback effects only play a minor role for the dynamics, at least under the undisturbed ozone conditions.

Acknowledgements. X. Zhu provided numerical code for his radiation scheme. The two-dimensional model data used for 


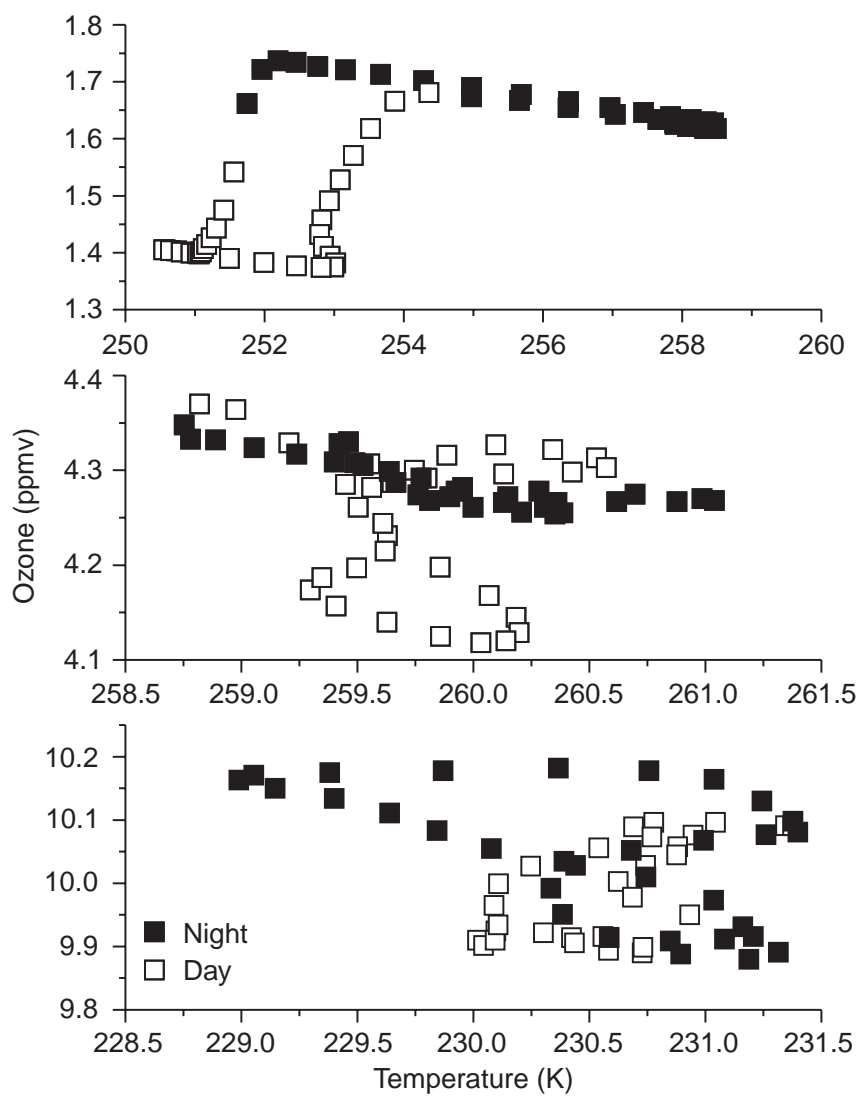

Fig. 18. Temperature and ozone at equator for 30 December at $0.5,2$ and $8 \mathrm{hPa}$

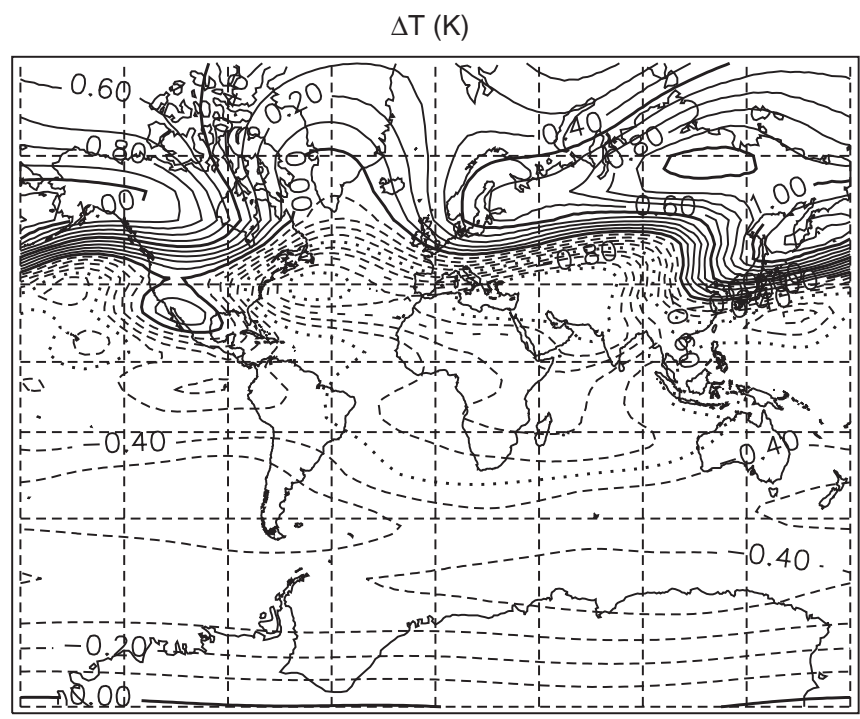

Fig. 20. Temperature difference of run R4-R2 for December 30, 1992, at $2 \mathrm{hPa}$. Contour interval $0.1 \mathrm{~K}$

initialisation were kindly supplied by J. U. Grooß. E. Chiou and U. Langematz gave us their climatological data in electronical form. The authors also want to thank two anonymous referees for their helpful comments and suggestions.

Topical Editor F. Vial thanks two referees for their help in evaluating this paper.
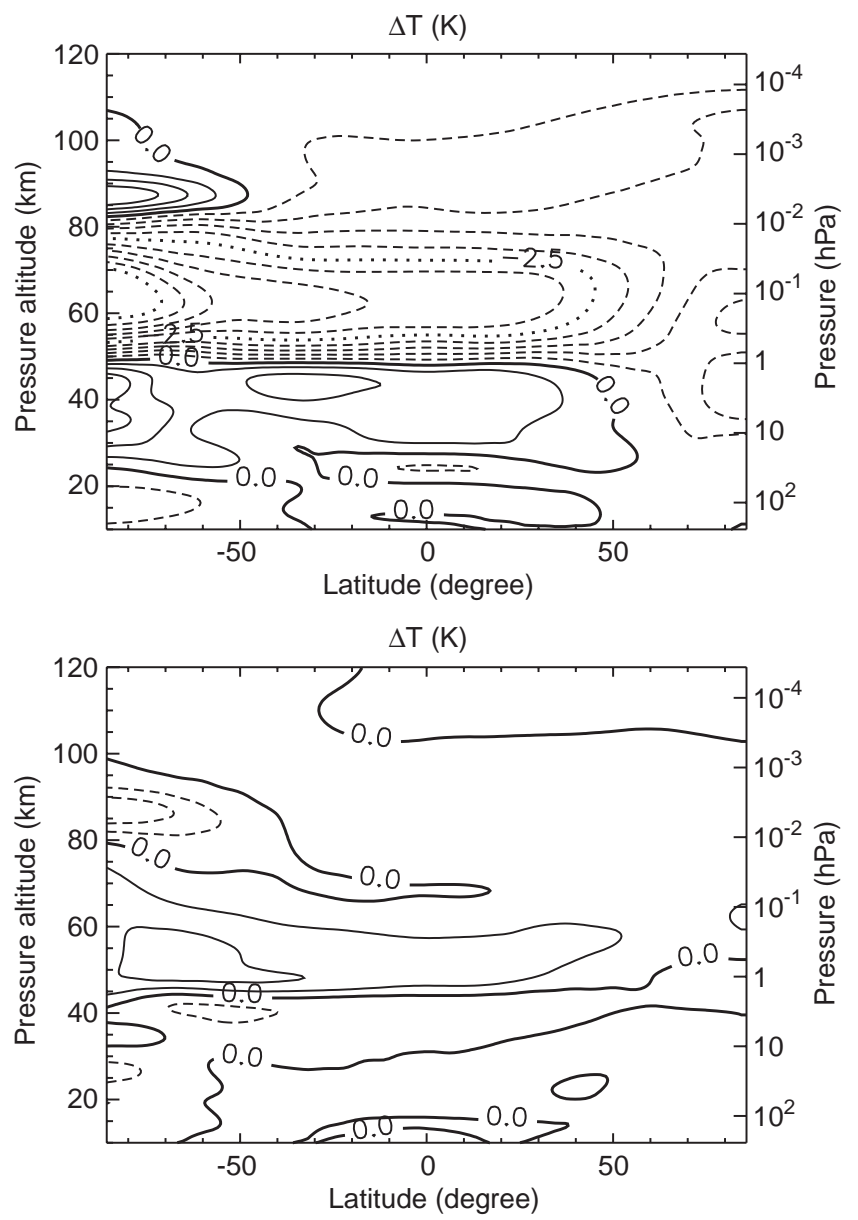

Fig. 19. December zonal mean values of the temperature difference of run R3-R2 (top) and R4-R2 (bottom). Contour interval $0.5 \mathrm{~K}$

\section{References}

Austin J., N. Butchart, and R. Swinbank, Sensitivity of ozone and temperature to vertical resolution in a gem with coupled stratospheric chemistry, Q. J. R. Meteorol. Soc., 123, 14051431, 1997.

Boris, J. P., and D. L. Book, Flux-corrected transport, I, a fluid transport algorithm that works, J. Comput. Phys., 11, 38-69, 1973.

Boville, B., Middle atmosphere version of CCM2 (MACCM2): annual cycle and variability, J. Geophys. Res., 100 (D5), 90179039, 1995.

Brasseur, G., and S. Soloman, Aeronomy of the Middle Atmosphere, D. Reidel, Dordrecht, 2nd edn, 1986.

Carslaw, K., B. Luo, and T. Peter, An analytic expression for the composition of aqueous $\mathrm{HNO}_{3}-\mathrm{H}_{2} \mathrm{SO}_{4}$ stratospheric aerosols including gas phase removal of $\mathrm{HNO}_{3}$, Geophys Res. Lett., 22, 1877-1880, 1995.

Chiou, E., M. McCormick, and W. Chu., Global water distributions in the stratosphere and upper troposphere derived from 5.5 years of SAGE II observations (1986-1991), J. Geophys. Res., 102, 19105-19118, 1997.

Chipperfield, M., J. Pyle, C. Blom, N. Glatthor, M. Höpfner, T. Gulde, C. Piesch, and P. Simon, The variability of $\mathrm{ClONO}_{2}$ and $\mathrm{HNO}_{3}$ in the arctic polar vortex: comparison of Transall Michelson interferometer for passive atmospheric sounding measurements and three-dimensional model results, J. Geophys. Res., 100, 9115-9129, 1995. 
Christiansen, B., A. Guldberg, A. Hansen, and L. Riishøjgaard, On the response of a three-dimensional general circulation model to imposed changes in the ozone distribution, J. Geophys. Res., 102 (D11), 13051-13077, 1997.

Crutzen, P., J.-U. Grooß, C. Brühl, and J. Russell III, A reevaluation of the ozone budget with HALOE UARS data: no evidence for the ozone deficit, Science., 268 (5211), 705-708, 1995.

DeMore, W., S. Sander, D. Golden, R. Hampson, M. Kurylo, C. Howard, A. Ravishankara, C. Kolb, and M. Molina, Chemical kinetics and photochemical data for use in stratospheric modeling, evaluation number 12, JPL Publications, pp 97-4, 1997.

Drdla, K., and R. Turco, Denitrification through PSC formation: A 1-d model incorporating temperature oscillations, J. Atmos. Chem., 12, 319-366, 1991.

Eckman, R., W. Grose, R. Turner, W. Blackshear, J. Russell III, L. Froidevaux, J. Waters, J. Kumer, and A. Roche, Stratospheric trace constituents simulated with a three-dimensional general circulation model: comparison with UARS data, J. Geophys. Res., 100, 13951-13966, 1995.

Fels, S., J. Mahlman, M. Schwarzkopf, and R. Sinclair, Stratospheric sensitivity to perturbations in ozone and carbon dioxide; radiative and dynamical response, J. Atmos. Science, 37, 22652297, 1980.

Fomichev, V., and G. Shved, Parametrization of the radiative flux divergence in the $9.6 \mu \mathrm{m} \mathrm{O}_{3}$ band, J. Atmos. Terr. Phys., 47, 1037-1049, 1985.

Fomichev, V., A. Kutepov, R. Akmaev, and G. Shved, Parametrization of the $15 \mu \mathrm{m} \mathrm{CO} 2$ band cooling in the middle atmosphere (15-115 km), J. Atmos. Terr. Phys., 55, 7 18, 1993.

Fortuin, J., and U. Langematz, An update on the global ozone climatology and on concurrent ozone and temperature trends, in Atmospheric Sensing and Modeling, vol 2311, pp 207-216. SPIE Proc. Int. Soc. Opt. Eng., Bellingham. 1994.

Freidenreich, S., and V. Ramaswamy, Solar radiation absorption by $\mathrm{CO}_{2}$, overlap with $\mathrm{H}_{2} \mathrm{O}$, and a parametrization for general circulation models J. Geophys. Res., 98, 7255-7264, 1993.

Froidevaux, L., M. Allen, S. Berman, and A. Daughton, The mean ozone profile and its temperature sensitivity in the upper stratosphere and lower mesosphere: an analysis of LIMS observations, J. Geophys. Res., 94, 6389-6417, 1989.

Gille, J. et al., Accuracy and precision of cryogenic limb array etalon spectormeter (CLAES) temperature retrievals, J. Geophys. Res., 101, 9583-9601, 1996.

Grooß, J.-U., Modelling of Stratospheric Chemistry Based on HALOE/UARS Satellite Data, PhD thesis, Universität Mainz, 1996.

Hanson, D., and K. Mauersberger, Laboratory studies of the nitric acid trihydrate: Implications for the south polar stratosphere, Geophys. Res. Lett., 15, 855-858, 1988.

Huang, F. T., C. A. Reber, and J. Austin, Ozone diurnal variations observed by UARS and their model simulation, J. Geophys. Res., 102, 12971-12985, 1997.

Hurrell, J. W., Comparison of ncar community climate model (CCM) climates, Clim. Dyn., 11, 25-50, 1995.

Kiehl, J. T., and B. A. Boville, The radiative-dynamical response of a stratospheric-tropospheric general circulation model to changes in ozone J. Atmos. Sci., 45(12) 1798-1817, 1988.

Kouker, W., Evaluation of dynamical parameters with a 3-D mechanistic model of the middle atmosphere, J. Geophys. Res., 98, 23165-23191, 1993.

Kouker, W., The Karlsruhe simulation model of the middle atmosphere version 1, Wissenschaftliche Berichte des Forschungzentrums Karlsruhe, FZKA 5635, 1995.

Kouker, W., A. Beck, H. Fischer, and K. Petzoldt, Downward transport in the upper stratosphere during the minor warming in February 1979, J. Geophys. Res., 100, 11069-11084, 1995.

Kumer, J., et al., Comparison of correlative data with $\mathrm{HNO} 3$ version 7 from the CLAES instrument deployed on the NASA upper atmosphere research satellite, J. Geophys. Res., 101, 9621-9656, 1996.
Langematz, U., and S. Pawson, The Berlin troposphere-stratosphere-mesosphere GCM: Climatology and forcing mechanisms, Q. J. R. Meteorol. Soc., 123, 1075-1096, 1997.

Langematz, U., T. Kubitz, and G. Radek, Die Spezifikation von Ozon in Klimamodellen und ihre Auswirkungen auf das Modellklima,. Ann. Meteorol., 34, 11-12, 1997.

Lefèvre, F., G. Brasseur, I. Folkins, A. Smith, and P. Simon, Chemistry of the 1991-1992 stratospheric winter: three-dimensional model simulations, J. Geophys. Res., 99, 8183-8195, 1994.

Lindzen, R., Turbulence and stress owing to gravity wave and tidal breakdown, J. Geophys. Res., 86, 9707-9714, 1981.

Luther, F.M., D.J. Wuebbles, and J.S. Chang., Temperature feedback in stratospheric model, J. Geophys. Res., 82, 49354942, 1977.

Manzini E., and L. Bengtsson, Stratospheric climate and variability from a general circulation model and observations. Clim. Dyn., 12, 615-639, 1996.

Müller, R., and T. Peter, The numerical modelling of the sedimentation of polar stratospheric cloud particles, Ber. Bunsenges. Phys. Chem. 96, 351-363, 1992.

Poole, L., and M. McCormick, Polar stratospheric clouds and the Antarctic ozone hole, J. Geophys. Res., 93, 13083-13089, 1988.

Ramanathan, V., and R. Dickinson, The role of stratospheric ozone in the zonal and seasonal radiative energy balance of the earthtroposphere system. J. Atmos. Sci., 36, 1084-1104, 1979.

Rasch, P., B. Boville, and G. Brasseur, A three-dimensional general circulation model with coupled chemistry for the middle atmosphere, J. Geophy. Res., 100, 9041-9071, 1995.

Rees, D., J. Barnett, and K. Labitzke, Cospar international reference atmosphere: 1986 part ii: middle atmosphere models, Adv. Space Res., 10(12), 1990.

Roche, A., J. Kumer, J. B. Mergenthaler, G. Ely, W. Uplinger, J. Potter, T. James, and L. Sterrit, The cryogenic limb array etalon spectrometer (CLAES) on UARS: experiment description and performance, J. Geophys Res., 98, 10763-1075, 1993.

Roe, P. L., and M. J. Baines, Algorithms for advection and shock problems, in Ed H. Viviand, Proc. 4th GAMM conference on numerical methods in fluid mechanics, Vieweg, 1982.

Röth, E. -P., A fast algorithm to calculate the photon flux in optically dense media for use in photochemical models, Ber. Bunsenges. Phys. Chem., 96, 417-420, 1992.

Schoeberl, M. R., and D. F. Strobel, The response of the zonally averaged circulation to stratospheric ozone reductions, $J$. Atmos. Sci., 35, 1751-1757, 1978.

Siskind, D., B. Connor, R. Eckman, E. Remsberg, J. Tsou, and A. Parrish, An intercomparison of model ozone deficits in the upper stratosphere and mesosphere from two data sets, $J$. Geophys. Res., 100, 11191-11201, 1995.

Smith, A. K., Numerical simulation of global variations of temperature, ozone and trace species in the stratosphere, $J$. Geophys. Res., 100, 1253-1269, 1995.

Steil, B., M. Dameris, C. Brühl, P. Crutzen, V. Grewe, M. Ponater, and R. Sausen, Development of a chemistry module for GCMs: first results of a multi-annual integration, Ann. Geophysicae, 2, 205-228, 1998.

Strobel, D. F., Parameterization of the atmospheric heating rate from 15 to $120 \mathrm{~km}$ due to $\mathrm{O}_{2}$ and $\mathrm{O}_{3}$ absorption of solar radiation, J. Geophys Res., 83, 6225-6230, 1978.

Thomason, L., L. Poole, and T. Deshler, A global climatology of stratospheric aerosol surface area density deduced from stratospheric aerosol and gas experiment II measurements, $J$. Geophys. Res., 102, 8967-8976, 1997.

World Meteorological Organization (WMO), Scientific assessment of ozone depletion, Global Ozone Research and Monitoring Project, Rep. 37, 1994.

Zhao, X., R. P. Turco, C, -Y. J. Kao, and S. Elliott, Numerical simulation of the dynamical response of the Arctic vortex to aerosol-associated chemical perturbations in the lower stratosphere, Geophys. Res. Lett., 23 (12), 1525-1528, 1996.

Zhu, X., An accurate and efficient radiation algorithm for middle atmosphere models, J. Atmos. Sci., 51 (24), 3593-3614, 1994. 